\author{
Pilar Úcar Ventura \\ Universidad Pontificia Comillas (Madrid) \\ pucar@comillas.edu
}

\title{
Leer cine: Alatriste como estrategia didáctica para la escritura
}

\section{Resumen:}

Este trabajo se propone revisar y analizar diferentes cuestiones gramaticales en relación con las actividades presentadas en el aula de Lengua española para estudiantes de Traducción e Interpretación y Relaciones Internacionales, tras la lectura del guion de la película Alatriste, para la competencia de la escritura. La metodología descriptiva por la que apostamos parte de la selección de algunas escenas de dicho guion para profundizar en las propiedades textuales por medio de la participación cognoscitiva y creativa del receptor.

Palabras clave: escritura, lectura, script, competencias, discurso

\begin{abstract}
:
Reading Films: Alatriste a Didactic Strategy for Writing

This study attempts to review and analyze a number of grammatical issues related to activities after the reading of Alatriste's film script, in the Spanish classroom for students of Translation and International Relations, and, in that way, to develop their writing abilities. We propose a descriptive methodology whereby a selection of scenes from the script in question is used in order deepen the textual properties through cognitive and creative participation on the part of the receiver.
\end{abstract}

Keywords: writing, reading, script, skills, speech 


\section{Introducción}

Consideramos que la lengua es instrumento de comunicación y no de manera exclusiva un objeto de conocimiento en sí mismo. Su enseñanza busca no solo el desarrollo de la competencia ${ }^{1}$ lingüística, objetivo último de los métodos estructurales, sino el de la competencia comunicativa ${ }^{2}$, la cual, de acuerdo con los presupuestos establecidos por Canale (1982: 83), consiste en la capacidad de comprender y producir textos sensu lato, esto es, «enunciado o conjunto coherente de enunciados que proporcionan el conocimiento y la habilidad para usar la lengua de manera significativa y real». Esa es la razón por la que, para el aprendizaje de una lengua, se abordan los aspectos funcionales y contextuales del material lingüístico (Littlewood, 1981: 248), y se persigue dotar al discente de recursos léxicos y gramaticales, pero también de mecanismos y estrategias para comprender textos, favorecer el discurso y solucionar problemas de comunicación, así como de información socio-cultural, entre otros medios. Apoyamos, por lo tanto, una metodología vertebrada en dos ejes de aprendizaje: los contenidos necesarios para la comunicación (nociones, funciones y estructuras lingüísticas) y los procesos de comunicación. Sobre esos dos ejes, según la teoría de Long y Sato (1983: 272), se generan las actividades comunicativas que se llevan a cabo en el aula.

Consideramos que tanto para los estudiantes heritage speakers como para el resto del alumnado resulta de gran importancia el dominio y estudio estandarizado de las competencias comunicativa y cultural puesto que reporta oportunidades para tomar parte en interacciones comunicativas significativas. Por ello, el aula como espacio de

${ }^{1}$ La vigésima segunda edición del DRAE define competencia en la $2^{\mathrm{a}}$ acepción como 'pericia, aptitud, idoneidad para hacer algo o intervenir en un asunto determinado'. Se trata de enseñar para comunicar a partir de un análisis de las necesidades.

${ }^{2}$ El conocimiento del sistema lingüístico no garantiza el éxito de un acto comunicativo. Para ser competente en la comunicación, el usuario ha de añadir otros recursos, capacidades y habilidades a los estrictamente lingüísticos. Sin ellos, la comunicación no tendría éxito (Canale, 1982: 81). 
comunicación debe albergar actos comunicativos verídicos y hablantes altamente competentes que acerquen lo más posible a los alumnos al éxito del resultado final (enfoque por tareas ${ }^{3}$ ). En ese contexto, el aprendiz es «agente activo en la construcción de los conocimientos y se concibe el aprendizaje como la apropiación de unos saberes que se interrelacionan con unos conocimientos adquiridos, en un complejo proceso de construcción y reconstrucción» (Camps, 2001: 8).

\section{Objetivos}

Se pretende facilitar, pues, el conocimiento del mismo código en función de la cultura, situaciones, contexto y registros, para que el proceso comunicativo se realice con éxito. En ese sentido, descifrar un contenido que se presenta entre diferentes interlocutores contribuye al avance y desarrollo de los procesos de enseñanza y aprendizaje de una lengua. En este marco no se puede entender el aprendizaje como modelo de trasmisión de información con el fin de que el alumnado lo integre de manera pasiva (Cassany, 1993: 76).

Hemos querido llevar el cine a las aulas a través de su lectura para aunar así un hecho cultural de importante repercusión social y mediática, ampliamente elogiado por la mayoría de la población, con la actividad académica configurada en los planes de estudio. Con ello pretendemos facilitar al profesor de diferentes disciplinas y de diversos niveles educativos el ejercicio de su oficio: la enseñanza y la adquisición de unos conceptos exigidos por las programaciones didácticas.

${ }^{3}$ Una tarea se caracteriza por ser representativa de procesos de comunicación de la vida real, a la vez que se identifica como unidad de actividad en el aula, donde se practica con un objetivo, estructura y secuencia de trabajo para conseguir la manipulación intencionada de información y significados; por lo tanto, la tarea será el dispositivo que permita a los alumnos aprender a aprender, pues para ello usan la lengua que están adquiriendo. 


\section{Metodología}

Al trabajar con el script (guion de cine leído), y a pesar de la novedad que puede suponer, los estudiantes saben que se trata de una lectura de cine, y no de literatura ni de géneros como la novela, la poesía o el teatro -muy útiles, por otra parte-; de ahí que dicho material cuente con la ventaja de que conocen el tipo de comunicación que se va a establecer entre el proceso de la lectura y ellos mismos.

El guion supone un material auténtico y real, máxime si ya se conoce la película y se ha visto en una sala, con lo que se enriquece el proceso de comunicación desde su génesis -creación del guion- hasta su momento final -el visionado de la cinta o la lectura de dicho guion-. Por eso, como se aprecia en el anexo incluido en el presente artículo, presentamos actividades precomunicativas (actividades estructurales y actividades cuasiestructurales) y actividades comunicativas (actividades de comunicación funcional y actividades de interacción social), más o menos guiadas en el uso de la lengua, pero concebidas para ir acercando de forma paulatina al estudiante a los usos espontáneos.

\section{Desarrollo}

El idioma está vinculado al contenido en una situación determinada. Los estudiantes, por lo tanto, percibirán la relación estrecha entre lengua y contenido y personajes, lo que les llevará a identificar las características del texto, a reflexionar sobre su especificidad, y a interpretar, versionar y recrear según las pautas que marcan las actividades para conseguir el objetivo deseado: un mayor y más profundo conocimiento de su propio idioma y la puesta en práctica de este conocimiento (Romera, 1999: 57). Nos gustaría aclarar que la finalidad de las actividades no consiste en la conclusión y entrega de un trabajo, sino en obtener, a partir de su realización, una plataforma de uso cotidiano en su proceso formativo (Nunan, 1998: 134). Los estudiantes son conscientes del reto que se les plantea: escribir con corrección y creatividad, en la medida de lo posible y siempre que lo favorezca el contexto. 
Las actividades, como se ha indicado antes, se organizan en cuatro bloques: de contenido, de estructura, de creación y de investigación comparativa, para trabajar la comprensión lectora, la expresión escrita, la creatividad y la expresividad, y las fuentes bibliográficas, respectivamente. Destacaríamos las estructurales, pues tienen que ver con el esqueleto lingüístico (léxico, sintaxis y registros idiomáticos). Por otro lado, las actividades de creación conllevan una lectura profunda que a su vez ha de conducir al análisis y la reformulación. Por último, se imbrica el guion en un contexto más amplio para vertebrarlo con otros géneros dentro de una cultura temática, según el contenido de la lectura (Cerrolaza, Cerrolaza, 1999: 97).

\subsection{El guion. Alatriste.}

En esta ocasión hemos seleccionado Alatriste, un relato de cierta complicación que abarca una gran variedad de temas: política, literatura, sociedad y economía, todo ello ubicado en el Siglo de Oro. Algunos de sus elementos pueden, además, dificultar la comprensión: léxico específico, fórmulas expresivas arcaicas, registro idiomático formal y culto, incluso comunicación no verbal. Al final de la presente exposición, se ofrecen como anexo las actividades creadas a partir del guion editado de Alatriste.

Esta obra nos permite ejercitar la competencia cultural (antes mencionada por Canale), así como la interacción comunicativa y el manejo del idioma en su contexto.

\subsection{La discursividad}

Un concepto que hemos incluido en las siguientes páginas ha sido el de discursividad, basada en un texto determinado, en un ámbito concreto. En nuestro caso, se traduce en la textualidad fílmica, muy relacionada con propiedades lingüísticas y culturales específicas, ya que constituye la expresión del comportamiento social a través de imágenes y palabras. Si la discursividad se presenta como una función social, el texto -el guion de cine- constituye la manifestación y realización concretas de las diferentes estructuras que configuran el código lingüístico; los textos, pues, son textos-en-función, es decir, se encuentran siempre en 
un contexto determinado, marcado, según algunos especialistas (Candlin, Murphy, 1990: 23), por criterios socio-comunicativos, en los que los estudiantes se ven involucrados por formar parte de una realidad socio-cultural que ellos conocen y consumen.

De estas premisas procede nuestro afán por favorecer el conocimiento y la práctica del código lingüístico, estimular la identificación, reflexión y posterior interpretación del contenido de ambos guiones, y así potenciar la capacidad para gestionar con eficacia la ingente información extraída, que puede de ese modo aplicarse a disciplinas y entornos transversales por medio del análisis y la síntesis. No olvidamos el trabajo autónomo, no aislado, responsable y efectivo. Según Escandell (1993: 243), la participación del receptor resulta no solo cognoscitiva, sino también imaginativa: tiene que utilizar sus conocimientos y capacidades para construir todo el mundo de ficción que se presenta ante sus ojos. Como afirman Rodríguez Melchor y Úcar Ventura (2014: 20),

el emisor da muchos datos pero es el receptor quien crea el marco en el que suceden las cosas, quien lleva a cabo finalmente la tarea de descodificación como actividad que facilita la construcción de significados vertidos en el texto; tal actividad -casi actitud- debe ser activa, siempre atenta y siempre cambiante, aunque se sabe que depende de cada sensibilidad, del estado temporal del ánimo y de los conocimientos individuales que singularizan -y posibilitan- la creación más plena.

En definitiva, se intenta aportar con la lectura una profunda reflexión sobre el propio idioma para detectar la coherencia y la cohesión del mensaje, y obtener una corrección lingüística completa, que propicie la relación de informaciones dispersas y su homogeneización solvente, adecuada y con propiedad.

\section{Conclusiones}

En los procesos de enseñanza/aprendizaje hemos optado por una enseñanza comunicativa, desglosada en enseñar para y aprender por. Resulta de gran importancia que el emisor -el profesor- motive 
e incentive al receptor -el discente- para que este comprenda significados y contenidos, y así recupere, reconozca y recuerde conocimientos; es decir, creemos que los textos escritos -en concreto los scripts-en su amplia tipología reparan y subsanan las carencias o deficiencias muchas veces diagnosticadas en la enseñanza de la lengua (Abril, Gonzalo, Peña-Marín, 1993: 72).

Hemos pretendido dar unas pinceladas de cómo se puede alcanzar una escritura competente a través de la práctica de algunas de las competencias más necesarias para desarrollar la redacción y la elaboración de un discurso tras la lectura reflexiva -con actividades pragmáticasde un guion de cine.

Todo ello se verá de manera más específica en el anexo que, como ya se ha anunciado líneas arriba, acompaña a estas páginas.

\section{Alatriste}

Se ofrecen a continuación una serie de actividades para su realización en el aula y fuera de ella, clasificadas conforme a una estructura conocida por el alumno a la hora de enfrentarse a la lectura de un texto (identificar el tema, los personajes, la lengua y el estilo):

1. actividades de contenido (desarrollo de la competencia de comprensión lectora);

2. actividades de estructura (desarrollo de la competencia de la expresión escrita);

3. actividades de creación (desarrollo de la competencia de la creatividad y expresividad);

4. actividades de investigación comparativa (desarrollo de la competencia bibliográfica).

En el grupo de actividades relativas al contenido encontramos un análisis exhaustivo del título, las ideas y los personajes que configuran la trama argumental. Las actividades centradas en la estructura se refieren al esqueleto lingüístico: léxico y sintaxis, por un lado, y registros idiomáticos, por otro. Las actividades de creación e invención se apoyan en una lectura profunda del guion y en la posibilidad que el análisis y la comprensión del mismo da al estudiante para crear 
e inventar a partir de lo leído. Por último, el apartado de investigación comparativa desea imbricar el guion en un contexto más amplio que trascienda la propia lectura y el visionado de la película para relacionarlo con otros géneros en un marco cultural de referentes similares.

Se trata principalmente de desarrollar las competencias de la expresión escrita y la comprensión lectora. Para ello se han articulado las actividades en una progresión adecuada hacia una mayor envergadura y una mayor complejidad de contenido, teniendo en cuenta la comunicación textual y el entorno cultural, para lograr una praxis real y auténtica; de ahí que se ofrezca el material lingüístico desde su aspecto funcional: en cada situación se identifican las intenciones comunicativas, pues el idioma actúa como elemento vehiculador y unificador, sin dejar de respetar la riqueza de la diversidad y el pluriculturalismo que subyace en todo script.

Deseamos aportar un elenco de actividades variado y sugestivo para agilizar la labor del profesor, dejándole margen de maniobra en su quehacer cotidiano, $\mathrm{y}$, a la vez, se trabaja con todos los componentes que forman el engranaje del idioma: de las unidades morfosintácticas a las supraoracionales. Las tareas han sido planteadas de forma abierta y permiten la integración de los diferentes perfiles y estilos de aprendizaje de los alumnos en el aula. Cada estudiante puede participar en la actividad que generará cada grupo según su nivel de competencia.

En esta ocasión nos hemos querido centrar en la vida del capitán mercenario Diego Alatriste, que vive una serie de aventuras en la España del Siglo de Oro, durante el reinado de Felipe IV y el gobierno de su valido el Conde-Duque de Olivares.

A través de sus episodios, se recompone una variada estampa social, política y cultural de nuestro siglo XVII.

Alatriste, guion de cine adaptado del libro Las aventuras del $\mathrm{Ca}$ pitán Alatriste de Arturo Pérez-Reverte, nos conduce a un momento de nuestro pasado histórico lleno de lances caballerescos, embozados, soldadesca, jerarcas apasionados, libertad y amos en un ambiente de vanidad. 


\section{ACTIVIDADES DE CONTENIDO}

\section{Contenido (desarrollo de la competencia de la comprensión lectora)}

1. Analiza el título del guion. Después de haber leído todo el guion, ¿podrías proponer otros títulos que se ajusten a la acción que acabas de conocer? Justifica tu elección.

2. Después de una primera lectura, señala los principales temas que aparecen en el guion y explica si se trata de una historia de libertad, de amor, de política, de guerra, de cultura, de amistad, de infidelidades y de traiciones...

Desde tu punto de vista, ¿hay algún tema que predomine sobre otro?

¿Existe una única línea argumental de la que se derivan otras secundarias? Apúntalas.

3. Hablando del final, ¿es previsible? ¿Puede existir otro diferente después de la derrota de la batalla en Rocroi? ¿Por qué?

Si creamos un nuevo final, ¿cambiaríamos el curso de la historia del Siglo de Oro? Inventa un final distinto en el que los personajes que luchan en la última escena vuelven victoriosos a Madrid a contar su triunfo.

4. Describe qué sentimientos has experimentado en los últimos momentos, en que la acción se precipita hacia el desastre y la derrota de los soldados españoles, que intentan resistir llenos de tensión.

Explica el sentido de la guerra, el orgullo de pertenecer a una nación y el ansia de defensa de un territorio. ¿Por qué has sentido esas reacciones?

¿Te has identificado con alguno de los personajes? ¿Con cuál? ¿Por qué?

5. Imagina que eres Íñigo de Balboa y consigues rescatar de la batalla final a Alatriste. Inventa una conversación entre los dos en la que se cuenten las impresiones del desastre de la batalla y del sinsentido de la guerra lejos de la patria; describe las sensaciones de estupor, sorpresa, pánico, rabia y deseos de sobrevivir al desastre.

6. En cuanto a los personajes, dibuja un cuadro sinóptico en el que aparezcan por un lado los personajes corales, grupales: los soldados, los mendigos, los tabernarios, los jerarcas...; y los personajes individuales; de estos señala los principales y los secundarios y establece las relaciones que predominan entre ellos.

De todos ellos, averigua cuáles fueron reales y existieron en la Historia de España. ¿Han cambiado en el guion sus funciones?

7. Diseña un listado de características psicológicas para los siguientes personajes:

- Alatriste

- Íñigo

- Angélica

- María de Castro 
- Pereira

- Felipe IV

¿Cuál de todos ellos es coherente con su pensamiento y acción? Explica los motivos que tienen para actuar cada uno de ellos de la manera en que lo hacen.

8. ¿Qué personajes sufren una evolución a lo largo de la historia? ¿Por qué?

¿Se trata de una madurez, de una paradoja, de un cambio en la actitud?

9. Di la función que tienen en el desarrollo de la acción los siguientes personajes, que aparecen en muy pocas escenas:

- la mujer de Malatesta;

- el esposo de María de Castro;

- la joyera.

10. ¿Qué características de misterio preceden a Alatriste antes de que lo conozcamos en la primera escena? Haz un listado de los rasgos de su personalidad vista a través de sus amigos, de İ̃igo, de los aristócratas.

¿Todos piensan lo mismo de él? ¿Todos le tratan igual? ¿Por qué?

11. Un amigo de Alatriste es el escritor Quevedo.Traza una línea de su personalidad a través del paso del tiempo en el guion.

12. Describe el papel que cumplen los siguientes escenarios, donde se desarrollan las principales escenas de la acción:

- la taberna del Turco;

- el frente de Flandes;

- el corral de comedias en Sevilla;

- las calles de Madrid;

- los garitos prohibidos;

- las calles;

- las salas palaciegas.

13. La acción de esta historia transcurre en las ciudades de Madrid, Sevilla, Cádiz, Breda y Rocroi. Investiga cómo son en la actualidad y haz una comparación de su situación en el siglo XVII y en el siglo XXI.

\section{Estructura (desarrollo de la competencia de la expresión escrita)}

\subsection{Léxico-semántica}

1. Selecciona los verbos y los adjetivos que hacen referencia a las luchas militares a lo largo de la acción y analiza si describen correctamente la atmósfera de combate.

Haz una clasificación de esos verbos, que también se podrían utilizar en otros contextos.

2. Comenta los recursos que generan el ambiente de misterio, de caos, de intrigas y de sospecha que predominan en algunas escenas. ¿Has encontrado algún momento en que domine el silencio? ¿El ruido es constante? ¿Por qué? 
3. Se trata de un guion en el que hay muchas acotaciones y muy extensas. ¿Qué función tienen? Parece una narración, una descripción... ¿Por qué no hay diálogo?

4. La rendición de Breda. Analiza los rasgos descriptivos que aparecen y que luego pinta Velázquez en su famoso cuadro titulado también Las lanzas.

¿Guarda relación la escritura con la pintura? ¿Se cumple la idea de que la descripción es pintar con palabras? ¿Por qué?

5. Analiza sintácticamente los siguientes párrafos y, para trabajar la síntesis, expresa, en una oración simple, cuál es la idea principal:

a) "Por su parte, Alatriste se las ve con Buckingham. Para su desconcierto, el caballero al que ataca, además de defenderse de las estocadas, no deja de vigilar, angustiado, la suerte que corre su compañero. Alatriste le arrincona contra la pared. Un mandoble de Alatriste le hace doblar la rodilla" (pág. 25).

b) "Os equivocáis. Todavía es fuerte... Olivares, como todos los tiranos, teme al pueblo como a una bestia feroz, pero los poderosos no le dan ningún miedo. Sabe cómo tratarlos: o los asusta o los destruye. Él es uno de ellos. En cuanto al pueblo, todavía no está preparado. Olivares caerá cuando Richelieu nos ponga de rodillas, no antes" (pág. 114).

c) "Cuando lo conocí, malvivía en Madrid alquilándose por cuatro maravedís en trabajos de poco lustre, a menudo en calidad de espadachín por cuenta de otros que no tenían la destreza o los arrestos para solventar sus propias querellas" (pág. $152)$.

6. Transformar las siguientes conversaciones en estilo directo al estilo indirecto:

a) GUALDALMEDINA

Bien, tú sabrás. Es tu cuello el que está en juego...pero, solo por curiosidad, ¿tú sabes a quién has estado a punto de matar esta noche?

\section{ALATRISTE}

No, Sr. Conde. Le doy mi palabra.

GUADALMEDINA

Te creo. Pero, entonces, ¿por qué no los mataste?

\section{ALATRISTE}

Tuve un presentimiento.

(pág. 28)

b) MARÍA

Mi marido se está muriendo. 


\section{ALATRISTE}

Lo siento.

\section{MARÍA}

Sí, pobre...El problema es que cuando se muera tendré que casarme con alguien. Ya sabes que no me gusta vivir sola. Y, al fin y al cabo, tú fuiste el primer hombre que conocí.

\section{ALATRISTE}

Soy pobre como las ratas.

(pág. 88)

7. Busca en el diccionario las siguientes palabras y haz una frase con cada una de ellas.

¿A qué campo semántico pertenecen?

Bravo, pisaverde, caponeras, pomo, memorial.

8. Explica el significado de los siguientes modismos y escribe una conversación entre los soldados amigos de Alatriste de forma que aparezcan todas ellas:

- frío luterano;

- protector de marranos;

- no perder comba.

Explica en qué contexto se pueden utilizar y a qué referencia histórica aluden.

\subsection{Estilística y registro idiomático}

1. Destaca algunos momentos de tensión y misterio provocados por la ambigüedad y polisemia de las expresiones que se usan; por ejemplo, cuando hablan en la taberna Quevedo y Alatriste.

2. ¿A través de qué recursos estilísticos adivinamos el paso del tiempo? ¿Son los personajes los que cambian? ¿Sus características físicas y psicológicas? ¿Los acontecimientos históricos?

3. Define las características del registro coloquial que marcan la lengua que usa la soldadesca. Compara estos rasgos con las expresiones de amor que usan Ínigo y Angélica cuando están juntos.

¿Es el tema el que determina la selección de expresiones y vocabulario? ¿Son los personajes y su rango social los que definen su propia lengua y registro idiomático?

4. Describe el vocabulario que usa el Conde-Duque de Olivares cuando se dirige a Alatriste y cómo le contesta este.

5. Pon palabras a los diferentes gestos y actitudes que se adjudican al rey Felipe IV: en sus salones, mientras se viste, en la escena de caza... 
6. Durante el episodio de la rendición de Breda, la escena se transforma en el cuadro de Velázquez. Imagina que tú eres Alatriste y estás junto al general don Ambrosio de Espínola, que recibe la llave de manos de don Justino de Nassau. En esta conversación cada personaje ha de hablar como le corresponde a su categoría social y se ha de mantener el registro idiomático propio de cada uno de ellos.

7. Aparecen diferentes elementos metafóricos referidos a la naturaleza: niebla, noche, frío...van anticipando el declive del amor, el fracaso, la soledad y la enfermedad... ¿A qué personajes afecta? ¿Cómo reaccionan? ¿Cambia su manera de expresarse?

8. Otro elemento muy literario y lleno de simbolismo es la presencia de la luna: se trata de algunos versos que ha escrito Quevedo. ¿Por qué es tan recurrente esta presencia de la luna? ¿Hay otros poetas que también la usan como recurso expresivo?

9. Reproduce el horror que puede sentir Íñigo en la última escena ocurrida en Rocroi, cuando ve cómo sus amigos caen ante el rechazo a la rendición que les proponen los franceses: utiliza adjetivos de sentimientos, sorpresa y algunas figuras retóricas que expresen la impresión que le causa asistir a la muerte de su amigo y protector Alatriste.

\section{Creación (desarrollo de la competencia de la imaginación y la expresividad)}

1. Selecciona un punto de la trama y añade dos escenas manteniendo personajes y estilo (acotaciones y registros idiomáticos) de forma que al retomar la historia no cambie el sentido lógico de las secuencias siguientes.

2. Inventa un nuevo personaje a la altura de la historia que tú quieras, pero en diferente momento que en la creación de las escenas del ejercicio anterior. Justifica su inclusión y la relación que mantiene con el resto de personajes. El personaje puede ser coral o individual, real o ficticio, animado o inanimado.

3. Inventa una conversación entre Íñigo y Angélica cuando él descubre que ella ha decidido en el último momento no acompañarle a Nápoles. Crea un nuevo final para su historia de amor.

4. Nos encontramos en la taberna del Turco en la que coinciden Cervantes, Lope, Góngora y Quevedo. Están hablando de su respectiva obra y del éxito o del fracaso que tienen con su público; tú también intervienes desde los conocimientos que tienes de ellos por tus clases de lengua y literatura.

5. Por parejas, plantead una conversación con Velázquez: os han regalado uno de los cuadros que aparece en el guion. Elegid cuál os gusta más y argumentad vuestra preferencia con razones a favor o en contra.

6. ¿Qué significado tiene la inclusión de varias escenas de la obra El perro del hortelano de Lope de Vega? ¿Se dirige María de Castro a alguien del público 
en concreto mientras interpreta a Diana? Describe cómo se consiguen los dos planos: el de la representación dentro del corral de comedias y el de la realidad de los espectadores que asisten a la función. Explicad por grupos el sentido del teatro dentro del teatro para justificar las acciones que se describen.

7. Conviértete en uno de los protagonistas de esta historia y deambula por las calles de Sevilla. Describe qué ves y qué haces, a quién encuentras durante los primeros años del siglo XVII. Intenta reproducir el habla de la época en tus diálogos con los personajes que te cruzas. Cuéntales cómo es ahora tu vida, unos siglos después, y cómo ha cambiado y evolucionado la historia: anúnciales la repercusión de las guerras, de las pinturas y la literatura de los artistas...

8. Imagina a Alatriste en tu ciudad durante el siglo XXI. Vas caminando y hablando con él. Reproduce la conversación que mantenéis sobre política, economía, ocio...

\section{Investigación comparativa (desarrollo de la competencia bibliográfica)}

1. (Actividad llevada a cabo fuera del aula seguida de una presentación en clase). Por grupos, investigad la importancia, la influencia y la jerarquía de las siguientes figuras en la época en que transcurre la acción: Felipe IV y el Conde-Duque de Olivares. Haced un listado de los principales acontecimientos históricos que España vivió durante su reinado.

2. Por parejas, recordad los tópicos literarios que habéis estudiado: amor platónico, amor omnia vincit, tempus fugit, vanitas vanitatis...Seleccionad las escenas en que aparecen estas ideas clásicas y a qué personajes afectan.

3. Por grupos, averiguad si existió la actriz María de Castro y si hubo otras actrices famosas de la época que representaron obras de Lope. Describid la relación que mantuvieron con el poder reinante.

4. (Actividad de discusión en clase). Analizad el poder que tenía la Iglesia en el Siglo de Oro: ¿de qué manera influía en la vida de los ciudadanos? ¿A qué religiones se nombra? ¿Qué función tenía el Tribunal de la Santa Inquisición? ¿Algún personaje del guion se ve afectado por dicho Tribunal? ¿Qué órdenes religiosas aparecen en el guion? ¿Qué características diferenciadoras tenían unas de otras?

5. En el guion se plantea la dicotomía de la pluma o la espada, las artes o las armas. ¿Conoces otra obra de la literatura en que se plantea dicha cuestión? ¿Por qué era tan importante ser soldado? ¿Qué otros oficios se desarrollaban en esta época? ¿Tiene algo que ver con el espíritu aventurero y de curiosidad por lo nuevo y los viajes típicos de este momento?

6. Buscad en grupos la estructura de los corrales de comedias en el Siglo de Oro y describidlo en clase. Comparad ese esquema con los teatros actuales $\mathrm{y}$ marcad las semejanzas y las diferencias. 
7. El concepto de monarquía queda en entredicho en varias escenas cuando se refiere las actividades del rey. Haced un listado del oficio real y de los cometidos que tenía Felipe IV como monarca de su época. ¿Cuál es su actitud ante su propio país? ¿Con qué ojos lo ven quienes lo rodean?

8. Por parejas, buscad información sobre el papel de las monarquías en la actualidad y haced una propuesta de la idea que aparece en el guion acerca del matrimonio real por conveniencia política. ¿Hoy se sostiene tal idea? ¿Por qué? Seleccionad artículos en diferentes periódicos que se hagan eco de estas ideas y expresad vuestra opinión al respecto.

9. ¿Conoces otras películas sobre esta misma época? Cita algunos títulos y haz una pequeña crítica comparando una de ellas con el guion que acabas de leer.

\section{Bibliografía}

CAMPS, A. (coord.) (2001), El aula como espacio de investigación y reflexión. Investigaciones en didáctica de la lengua, Graó, Barcelona.

CANALE, M. (1983), "From Communicative Competence to Communicative Language Pedagogy”, en: Richards, J. C., Schmidt, R. (eds.), Language and Communication, Longman, London-New York, pp. 72-145.

CANDLIN, C. N., MURPHY, D. F. (eds.) (1990), Language Learning Tasks, Lancaster, Prentice Hall.

CASSANY, D. (1993), Reparar la escritura. Didáctica de la corrección de lo escrito, Graó, Barcelona.

CERrolaZA, M., CERROlaZA, O. (1999), Cómo trabajar con libros de texto. La planificación de la clase, Edelsa, Madrid.

ESCANDELL-VIDAL, M. V. (1993), Introducción a la pragmática, Anthropos, Barcelona.

LIGHTBOWN, P. M. (1984), "The Relationship Between Theory and Method in Second Language Acquisition Research", en: Davies, A., Criper C., Howatt, A. P. R. (eds.), Interlanguage, Edinburgh University Press, Edinburgh, pp. 241-252.

LONG, M., SATO, C. J. (1983), "Classroom Foreigner Talk Discourse: Forms and Functions of Teachers 'Questions', en: Seliger, H. W., Long, M. H. (eds.), Classroom Oriented Research in Second Language Acquisition, Newbury House, Rowley, Mass., pp. 268-285. 
LOZANO, J., PEÑA-MARÍN, C., ABRIL, G., (1993), Análisis del discurso: hacia una semiótica de la interacción textual, Cátedra, Madrid.

NUNAN, D. (1998), El diseño de tareas para la clase comunicativa, Cambridge University Press, Cambridge.

RODRÍGUEZ MELCHOR, D., ÚCAR VENTURA, P. (eds.) (2014), Traducción e interpretación. Lectura y comprensión de textos especializados en ciencias de la salud, Universidad Pontificia Comillas, Madrid.

ROMERA, J. M. (1999), Juego de palabras, Gobierno de Navarra, Departamento de Educación y Cultura, Pamplona. 